\title{
ERRATUM
}

\section{From stem cell to T cell: one route or many?}

\section{Avinash Bhandoola and Arivazhagan Sambandam}

Nature Reviews Immunology 6, 117-126 (2006); doi:10.1038/nri1778

When published, the fifth row of Table 1 contained incorrect information and the eighth row was incorrectly aligned.

The corrected table is shown below.

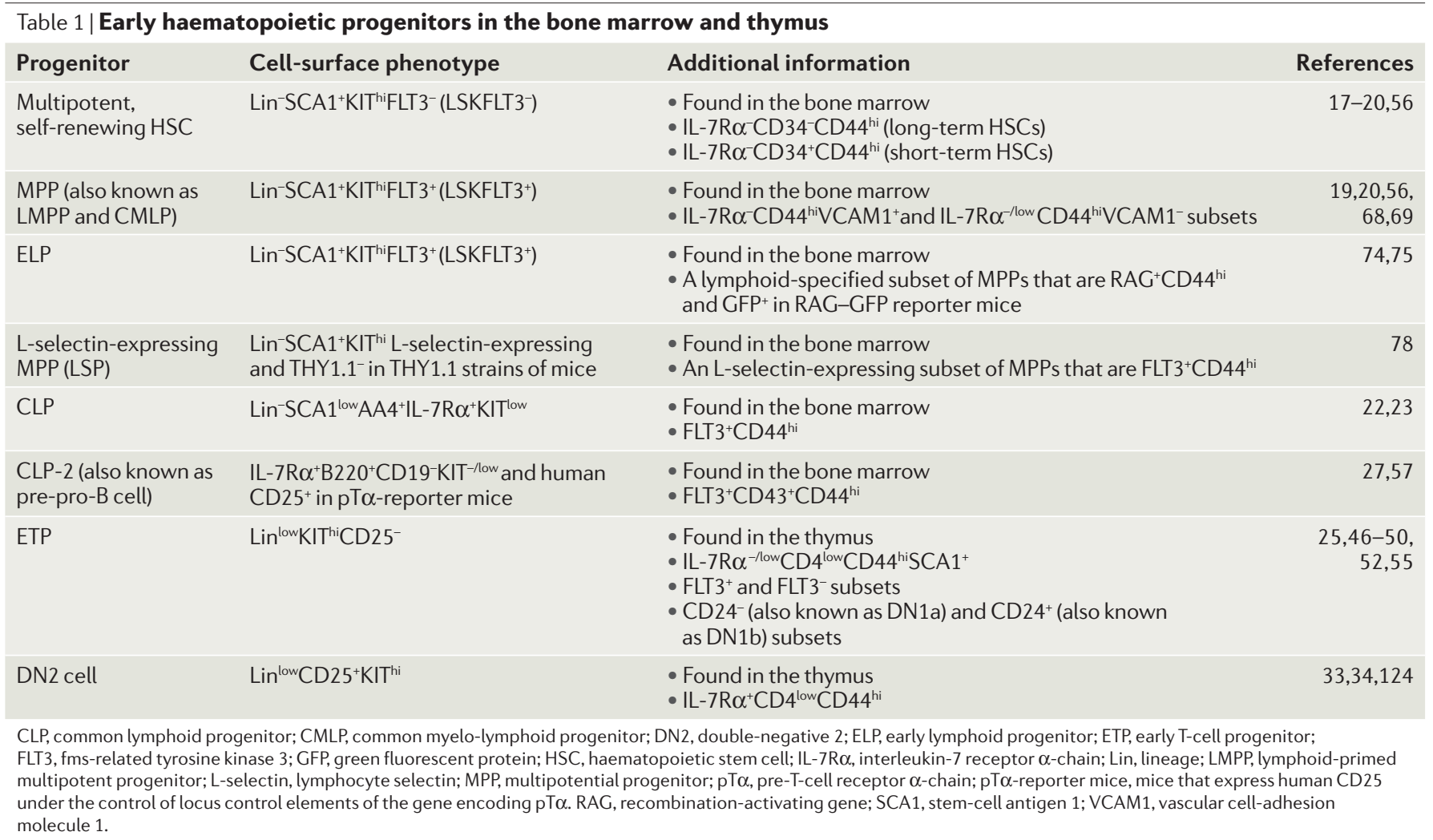

\section{ONLINE CORRESPONDENCE $\square$}

Nature Reviews Immunology publishes items of correspondence online. Such contributions are published at the discretion of the Editors and can be subject to peer review. Correspondence should be no longer than 500 words with up to 15 references and should represent a scholarly attempt to comment on a specific Review or Perspective article that has been published in the journal. To view correspondence, please go to our homepage and select the link to Correspondence, or use the URL indicated below.

The following correspondence has recently been published:

Promoting the learning of immunology in the developing countries: shaping the vision into a mission to alleviate human suffering worldwide

Ajit Singh

http://www.nature.com/nri/archive/correspondence.html

This correspondence relates to the article:

Promoting the learning of immunology in developing countries Jean-Jacques Fournié, Frédérique Gaits and Marc Bonneville

Nature Reviews Immunology 5, 893-898 (2005) 